\title{
Developmental Changes in the Interactions of Cholinergic and $\beta$-Adrenergic Agonists on Electrophysiologic Properties of Canine Cardiac Purkinje Fibers
}

\author{
JEFFREY P. MOAK,' ROBERT F. REDER, ${ }^{2}$ PETER DANILO, JR., AND MICHAEL R. ROSEN \\ Division of Developmental Pharmacology and the Departments of Pharmacology and Pediatrics, College of \\ Physicians and Surgeons of Columbia University, New York, New York
}

\begin{abstract}
The parasympathetic nervous system attenuates the effects of sympathetic interventions on the hearts of mature animals. Whereas the vagal mediator, acetylcholine (ACh), alone has minor effects on electrophysiologic properties of the ventricular conducting system, in the presence of sympathetic amines, it induces an accentuated antagonism. Because there are developmental changes in both sympathetic and parasympathetic effects on the heart we studied the parasympathetic and sympathetic interaction in isolated neonatal canine Purkinje fibers (PF), and compared the results to those in adult PF. PF were exposed to isoproterenol (Iso) alone $\left(1 \times 10^{-9}, 1 \times 10^{-7}\right.$ and $1 \times$ $\left.10^{-5} \mathrm{M}\right)$ to $\mathrm{ACh}$ alone $\left(1 \times 10^{-7}\right.$ or $\left.1 \times 10^{-5} \mathrm{M}\right)$ and to Iso in the presence of $\mathrm{ACh}$. In adult PF, superfusion with Iso, $10^{-5} \mathrm{M}$, alone shortened action potential duration to $50 \%$ repolarization from a control value of $215 \pm 9$ to $200 \pm 9$ ms $(p<0.01)$. Simultaneous superfusion of adult PF with Iso $10^{-5} \mathrm{M}$ and Ach $10^{-5} \mathrm{M}$ decreased the extent of action potential shortening produced by Iso, so that action potential duration to $\mathbf{5 0 \%}$ repolarization shortened from a control value of $221 \pm 8$ to only $214 \pm 12 \mathrm{~ms}(p<0.01)$. The response to superfusion with Iso and Ach $\left(10^{-5} M\right)$ differed significantly from that with Iso alone $(p<0.01)$. In contrast, exposure of neonatal PF to Iso $\left(10^{-5} \mathrm{M}\right)$ prolonged action potential duration to $50 \%$ repolarization from a control value of $157 \pm 7$ to $180 \pm 5 \mathrm{~ms}(p<0.01)$. No inhibition of the effect of Iso by Ach $\left(10^{-7}\right.$ or $\left.10^{-5} \mathrm{M}\right)$ was observed in neonatal PF. At neither age did $\mathrm{ACh}$, alone, exert a significant effect. Our data suggest that accentuated antagonism is not present in young animals having an immature autonomic nervous system, but that it occurs subsequent to maturation. (Pediatr Res 20: 613-618, 1986)
\end{abstract}

\section{Abbreviations}

Ach, acetylcholine

AP, action potential

Amp, action potential amplitude

$A D_{50}$, action potential duration to $\mathbf{5 0 \%}$ repolarization $\mathrm{APD}_{100}$, action potential duration to full repolarization MDP, maximum diastolic potential

Received May 28, 1985; accepted February 18, 1986

Address for correspondence Michael R. Rosen, M.D., Department of Pharmacology, College of Physicians and Surgeons of Columbia University, 630 West 168th Street, New York, NY 10032

Supported in part by USPHS NHLBI Grants HL-28958 and HL-07271.

${ }^{1}$ Present address Texas Children's Hospital, Division of Pediatric Cardiology, 6621 Fannin. Houston, TX 77030.

${ }_{2}$ Present address Knoll Pharmaceutical Company, 30 North Jefferson Road, Whippany, NJ 07981.

\author{
PF, Purkinje fiber bundles \\ $\dot{\mathrm{V}}_{\max }$, phase zero upstroke velocity \\ Iso, isoproterenol \\ $\mathrm{CL}$, cycle length
}

The interactions of the sympathetic and parasympathetic nervous systems have long been an area of interest. For example, Rosenblueth and Simone (1) found that the absolute reduction in heart rate produced by a vagal stimulus in anesthetized cats was greater when the basal heart rate previously had been increased by sympathetic stimulation. Further study of this interaction has led to the concept of accentuated antagonism $(2,3)$; i.e. stimulation of parasympathetic efferent nerves has little depressant effect on heart rate or contractility; but the greater the background level of sympathetic activity, the more profound is the depressant effect of a given vagal stimulus (4-7). The net result of the inhibitory effect of cholinergic activation is not simply an algebraic sum of the respective activities of the sympathetic and parasympathetic nervous systems; but is greater in magnitude as sympathetic activation is increased $(2,8,9)$.

There were two reasons for performing the present study. First, although Ach inhibits the electrophysiologic effects of sympathetic stimulation of adult canine PF (10-12), and the effects of cholinergic input depend on the prevailing level of sympathetic activity $(2,8,9)$, we are not aware of whether such accentuated antagonism occurs in younger animals. Second, although postnatal development occurs in both limbs of the autonomic nervous system (13), there are different degrees of maturity of the sympathetic (relatively low) $(14,15)$ and the parasympathetic (relatively high) nervous system (16) at birth. We questioned whether the different levels of development of autonomic input at birth and in the adult might be associated with differences in the response to combinations of sympathetic and parasympathetic agonists.

\section{METHODS}

We anesthetized adult mongrel dogs, weighing 10 to $20 \mathrm{~kg}$, and 1- to 10-day-old beagles and mongrels with sodium pentobarbital, $30 \mathrm{mg} / \mathrm{kg}$, intravenously (adults) and intraperitoneally (neonates). The heart was quickly removed and placed in cold oxygenated Tyrode's solution. Free running PF were excised from the right and the left ventricle and placed in a Lucite tissue bath perfused with Tyrode's solution containing (mmol/liter): $\mathrm{NaCl}, 131 ; \mathrm{NaHCO}_{3}, 18 ; \mathrm{CaCl}_{2}, 2.7 ; \mathrm{MgCl}_{2}, 0.5 ; \mathrm{NaH}_{2} \mathrm{PO}_{4}, 1.8 ;$ $\mathrm{KCl}, 4.0$; and dextrose, 5.5 . The Tyrode's solution was bubbled with $95 \% \mathrm{O}_{2}-5 \% \mathrm{CO}_{2}$ and warmed to $37^{\circ} \mathrm{C}(16)$. 
Stimuli were delivered with bipolar silver wires that were insulated to the tips with Teflon. The stimulus pulse width was $2 \mathrm{~ms}$ and amplitude was 1.5 to 2 times diastolic threshold. The preparations were impaled with $3 \mathrm{M} \mathrm{KCl-filled} \mathrm{glass} \mathrm{capillary}$ microelectrodes having tip resistances of 10-30 M $\Omega$. The PF were paced at a cycle length of $800 \mathrm{~ms}$ and allowed to stabilize for 1 $\mathrm{h}$ before control measurements were made. After equilibration the following transmembrane action potential characteristics were measured from photographic recordings: MDP (measured from 0 potential to the maximum level of polarization following phase 3); action potential amplitude; (measured from the MDP to the peak of the phase 0 overshoot) maximum upstroke velocity of phase zero $\left(\dot{\mathrm{V}}_{\max }\right)$, which was differentiated electronically $(6)$; plateau height (measured from " 0 " potential to the peak of the plateau); and $A \mathrm{AD}_{50}$ and $A P D_{100}$. The methods used to calibrate the equipment and record action potential data have been described previously (17).

In previous studies we have shown adult PF to have significantly higher maximum diastolic potentials, action potential amplitudes and $\dot{\mathrm{V}}_{\max }$, and longer action potential durations than neonatal fibers (15). In the present study we attempted to minimize MDP, amplitude and $\dot{\mathrm{V}}_{\max }$ as variables, and so, selected impalements for which these were comparable. We have used this method in previous pharmacologic studies, because by obtaining comparable control values across groups, we leave age as the predominant variable in considering differences in drug effects (18). In the present study, action potential duration differs at both ages, and we deliberately did not select fibers with similar durations, as this would have required our impaling non-comparable sites in the conducting system (i.e. we would have substituted variation in the site in the conduction system for variation in repolarization) (19).

We studied three groups of fibers (Table 1). Each group was superfused with 1 -Iso $d$-bitartrate (Sigma) $1 \times 10^{-9}, 1 \times 10^{-7}$, and $1 \times 10^{-5} \mathrm{M}$. The first group received Iso alone. Some of these fibers served as the controls for the subsequent Ach experiments in which drive CL was $800 \mathrm{~ms}$. Others were subjected to changes in drive cycle length from 1000 through $300 \mathrm{~ms}$ during control and isoproterenol superfusion. The second group was superfused initially with Ach chloride (Sigma) $1 \times 10^{-7} \mathrm{M}$, alone, and then with graded concentrations of isoproterenol in the presence of Ach $1 \times 10^{-7} \mathrm{M}$. The third group was superfused initially with Ach $1 \times 10^{-5} \mathrm{M}$, alone, and then with graded concentrations of Iso in the presence of Ach $1 \times 10^{-5} \mathrm{M}$. Steady state effects were achieved within $10 \mathrm{~min}$ of onset of superfusion with Ach and/or Iso.

Na EDTA, $5 \times 10^{-5} \mathrm{M}$, was added to all solutions containing Iso to prevent oxidation. We previously have shown this to exert no effect on the transmembrane potentials of adult fibers (15). In seven preliminary experiments we studied its effects on neonatal fibers having the following transmembrane potential characteristics at $\mathrm{CL}=800 \mathrm{~ms}$ (values are control and EDTA, $5 \times$ $10^{-5} \mathrm{M}$, respectively; $\overline{\mathrm{x}} \pm \mathrm{SE}$ ): $\mathrm{MDP},-88 \pm 2,-88 \pm 1 \mathrm{mV}$; amplitude $126 \pm 1,126 \pm 1 \mathrm{mV} ; \dot{\mathrm{V}}_{\max } 501 \pm 32,521 \pm 38 \mathrm{~V} / \mathrm{s}$; $\mathrm{APD}_{50}, 169 \pm 9,168 \pm 9 \mathrm{~ms} ; \mathrm{APD}_{100}, 292 \pm 8,288 \pm 9 \mathrm{~ms}$ ( $p>0.05$ for all variables).

Data Analysis. Only results from experiments in which a continuous impalement was maintained throughout the superfusion protocol were included in the data analysis. A nested analysis of variance and Scheffe's test were used to assess statistically significant differences between the two groups (20). For Scheffe's test $p<0.1$ was considered significant (20). Results are expressed as the mean \pm SEM.

\section{RESULTS}

The responses of neonatal and adult PF to superfusion with Iso differed significantly (Table 2). Iso $1 \times 10^{-7}$ and $1 \times 10^{-5} \mathrm{M}$ consistently shortened action potential duration of adult PF. In the 17 fibers studied, Iso $1 \times 10^{-5} \mathrm{M}$ decreased $\mathrm{APD}_{50}$ from a control value of $215 \pm 9$ to $200 \pm 9 \mathrm{~ms}(p<0.01)$. In contrast, Iso $1 \times 10^{-5} \mathrm{M}$ prolonged $\mathrm{APD}_{50}$ of 11 neonatal fibers from a control value of $157 \pm 7$ to $180 \pm 5 \mathrm{~ms}(p<0.01)$. Similarly, $\mathrm{APD}_{100}$ increased from a control value of $261 \pm 8$ to $270 \pm 6 \mathrm{~ms}$ $(p<0.05)$. Action potential recordings from two experiments are presented in Figure 1. For both adult and neonatal PF Iso had little effect on maximum diastolic potential, action potential amplitude or $\dot{\mathrm{V}}_{\max }$ (Table 2).

We analyzed the response of plateau height and the slopes of phases two and three of repolarization to superfusion with Iso.

Table 1. Experimental design-neonatal and adult $P F$

\begin{tabular}{ccc}
\hline Group I & \multicolumn{1}{c}{ Group II } & \multicolumn{1}{c}{ Group III } \\
\cline { 2 - 2 } $\begin{array}{c}\text { Drug-free } \\
\text { Tyrode's solution }\end{array}$ & $\begin{array}{c}\text { Drug-free } \\
\text { Tyrode's solution }\end{array}$ & \multicolumn{1}{c}{$\begin{array}{c}\text { Drug-free } \\
\text { Tyrode's solution }\end{array}$} \\
\hline Iso $10^{-9} \mathrm{M}$ & Ach $10^{-7} \mathrm{M}$ & Ach $10^{-5} \mathrm{M}$ \\
Iso $10^{-7} \mathrm{M}$ & Ach $10^{-7} \mathrm{M}+$ Iso $10^{-9} \mathrm{M}$ & Ach $10^{-5} \mathrm{M}+$ Iso $10^{-9} \mathrm{M}$ \\
Iso $10^{-5} \mathrm{M}$ & Ach $10^{-7} \mathrm{M}+$ Iso $10^{-7} \mathrm{M}$ & Ach $10^{-5} \mathrm{M}+$ Iso $10^{-7} \mathrm{M}$ \\
& Ach $10^{-7} \mathrm{M}+$ Iso $10^{-5} \mathrm{M}$ & Ach $10^{-5} \mathrm{M}+$ Iso $10^{-5} \mathrm{M}$ \\
\hline
\end{tabular}

Table 2. Effects of Iso on transmembrane action potential characteristics of adult and neonatal PF (mean $\pm S E M)$

\begin{tabular}{|c|c|c|c|c|c|}
\hline Iso concentration & $\begin{array}{c}\text { MDP } \\
(-\mathrm{mV})\end{array}$ & $\begin{array}{l}\text { Amp } \\
(\mathrm{mV})\end{array}$ & $\begin{array}{l}\dot{\mathrm{V}}_{\max } \\
(\mathrm{V} / \mathrm{s})\end{array}$ & $\begin{array}{c}\mathrm{APD}_{50} \\
(\mathrm{~ms})\end{array}$ & $\begin{array}{c}\mathrm{APD}_{100} \\
(\mathrm{~ms})\end{array}$ \\
\hline \multicolumn{6}{|l|}{ Adult PF $(n=17)$} \\
\hline Control & $91 \pm 2$ & $130 \pm 2$ & $567 \pm 29$ & $215 \pm 9$ & $340 \pm 10$ \\
\hline Iso $10^{-9} \mathrm{M}$ & $92 \pm 2$ & $130 \pm 2$ & $575 \pm 33$ & $213 \pm 10$ & $336 \pm 10$ \\
\hline Iso $10^{-7} \mathrm{M}$ & $92 \pm 2$ & $131 \pm 2$ & $583 \pm 34$ & $186 \pm 9^{*}$ & $298 \pm 10^{*}$ \\
\hline Iso $10^{-5} \mathrm{M}$ & $92 \pm 2$ & $131 \pm 2$ & $581 \pm 34$ & $200 \pm 9^{*}$ & $311 \pm 11^{*}$ \\
\hline \multicolumn{6}{|l|}{ Neonatal PF $(n=11)$} \\
\hline Control & $94 \pm 2$ & $133 \pm 2$ & $575 \pm 37$ & $157 \pm 7$ & $261 \pm 8$ \\
\hline Iso $10^{-9} \mathrm{M}$ & $95 \pm 2$ & $134 \pm 2$ & $573 \pm 38$ & $161 \pm 6$ & $259 \pm 7$ \\
\hline Iso $10^{-7} \mathrm{M}$ & $95 \pm 2$ & $135 \pm 2$ & $584 \pm 43$ & $169 \pm 7$ & $260 \pm 5$ \\
\hline Iso $10^{-5} \mathrm{M}$ & $95 \pm 2$ & $135 \pm 2$ & $561 \pm 39$ & $180 \pm 5^{*}$ & $270 \pm 6 \dagger$ \\
\hline
\end{tabular}

$* p<0.01$.

$\dagger p<0.05$. 
As shown in Figure 2, during control, the adult fibers had a higher plateau, and more gradual slopes of phases 2 and 3 than the neonatal fibers. Figure $2 A$ demonstrates a concentrationdependent increase of plateau height during superfusion with Iso for both age groups. However, the magnitude of the increase in plateau height was significantly greater for the neonatal fibers ( $p$ $<0.01)$. Plateau height in the adults increased from a control of
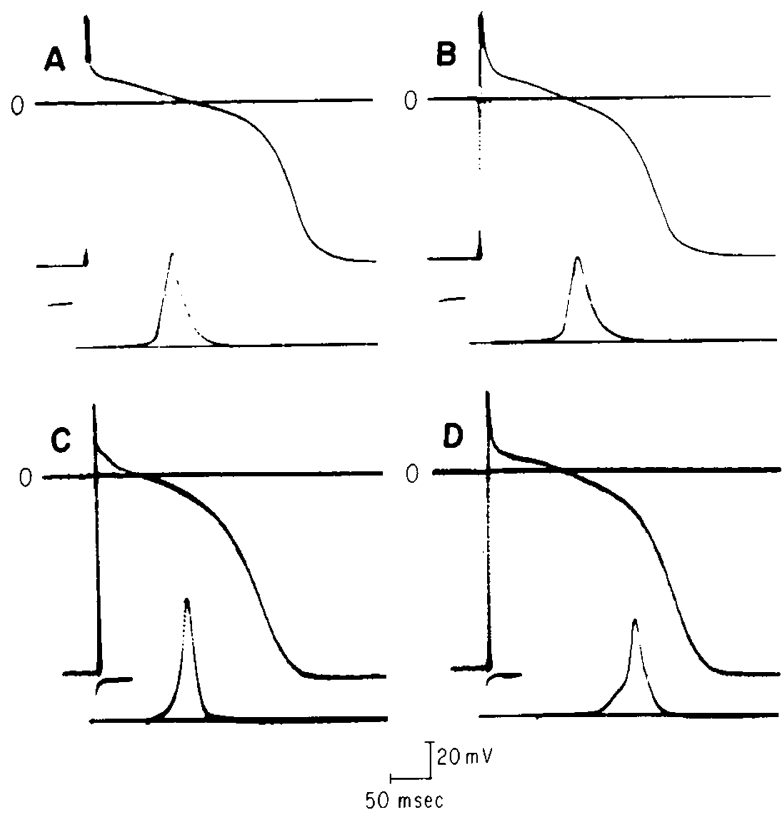

Fig. 1. The effect of Iso on transmembrane potentials of adult and neonatal canine cardiac PF. The upper trace in all panels shows the transmembrane potential and a 0 reference line, the lower, a $200 \mathrm{~V} / \mathrm{s}$ calibration followed by the electronically differentiated $\dot{\mathrm{V}}_{\max }$ of phase 0 . $A$, adult control. $B$, following superfusion with Iso $\left(1 \times 10^{-5} \mathrm{M}\right) . C$, neonatal control. $D$, following superfusion with Iso $\left(1 \times 10^{-5} \mathrm{M}\right)$. Calibrations: horizontal bar $=50 \mathrm{~ms}$; vertical bar $=20 \mathrm{mV}$.
$+11 \pm 1$ to $+13 \pm 2 \mathrm{mV}$ during superfusion with Iso $1 \times 10^{-7}$ $\mathrm{M}(p<0.01)$. Plateau height of neonatal PF increased from +7 \pm 2 to $+14 \pm 2 \mathrm{mV}(p<0.001)$. The response of the slope of phase two repolarization to Iso of the two age groups differed (Fig. $2 B)$. Iso $\left(10^{-7} \mathrm{~m}\right)$ significantly increased the slope of phase two repolarization from a control value of $0.16 \pm 0.05$ to $0.19 \pm$ $0.05 \mathrm{mV} / \mathrm{s}(p<0.01)$ in adult PF; whereas no significant change occurred in neonatal PF $(p>0.05)$. The change in slope of phase three repolarization of neonatal and adult PF on superfusion with Iso is shown in Figure $2 C$. Iso increased the slope of phase three of both adult and neonatal fibers $(p<0.01)$; but no significant difference was observed between the two age groups. These results suggest that the prolongation of repolarization of the neonatal action potential induced by Iso results from the increase in plateau height in the presence of an unchanging slope of phase 2 .

We also considered whether the effects of Iso on repolarization might vary with drive cycle length at both ages. For this reason we drove fibers in the control state at cycle lengths of 1000,800 , 500 , and $300 \mathrm{~ms}$. After determining the effect of cycle length on action potential duration, we superfused the preparations sequentially with Iso $1 \times 10^{-7}$ and $1 \times 10^{-5} \mathrm{M}$. At each concentration we repeated the drive protocol (Fig. 3). At all cycle lengths, Iso accelerated repolarization in the adult fibers. The effect was greatest at the longest drive cycle length, and was least at $\mathrm{CL}=$ $300 \mathrm{~ms}$. Moreover at the three longer cycle lengths, a maximum effect of Iso was seen at $1 \times 10^{-7} \mathrm{M}$.

In contrast, in the neonatal fibers, Iso prolonged repolarization at all cycle lengths. Again, the greatest effect was seen at 1000 $\mathrm{ms}$, and the least at $300 \mathrm{~ms}$. These results indicate the effects of Iso on repolarization in neonates and adults are qualitatively different (prolonging repolarization in the former and accelerating it in the latter). Nevertheless, the effects at both ages are cycle length dependent.

Effects of Ach on transmembrane action potential characteristics. Superfusion of adult and neonatal PF with Ach alone had no significant effects on the transmembrane potentials (Table 3).

Interaction between Iso and Ach. Figure 4 demonstrates the developmental changes that occurred in the effects of Iso and Ach on $\mathrm{APD}_{50}$. In adults, the concentration-response curve for
A

PLATEAU heIGHT

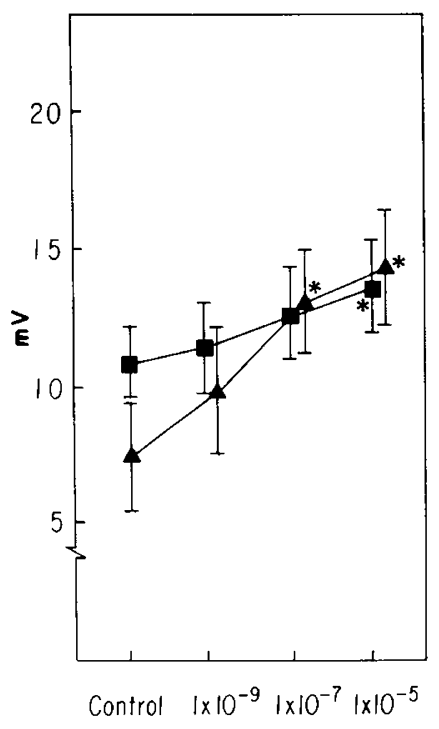

Iso (M)
B

SLOPE OF PHASE TWO

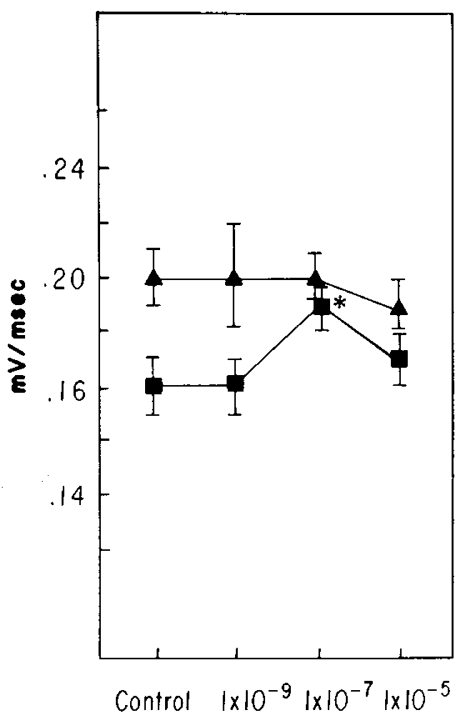

I SO $(M)$
C SLOPE OF PHASE THREE

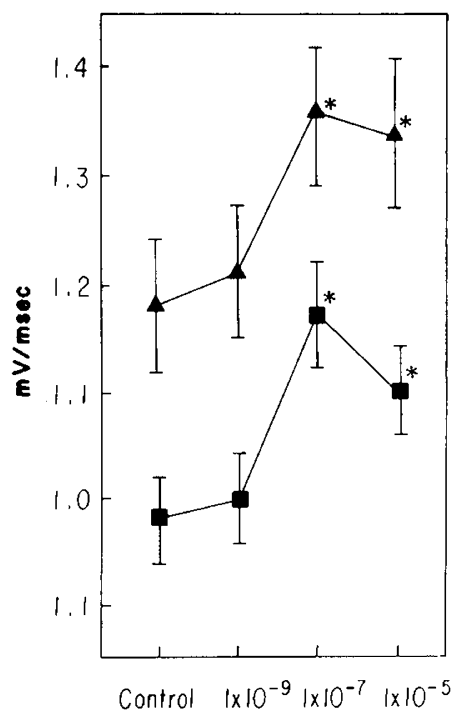

ISO (M)

Fig. 2. The influence of Iso on repolarization of neonatal and adult PF. $A$, response of plateau height to superfusion with Iso. $B$, response of the slope of phase 2 repolarization to superfusion with Iso. $C$, response of the slope of phase 3 repolarization to superfusion with isoproterenol (mean \pm

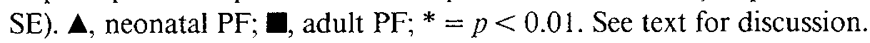




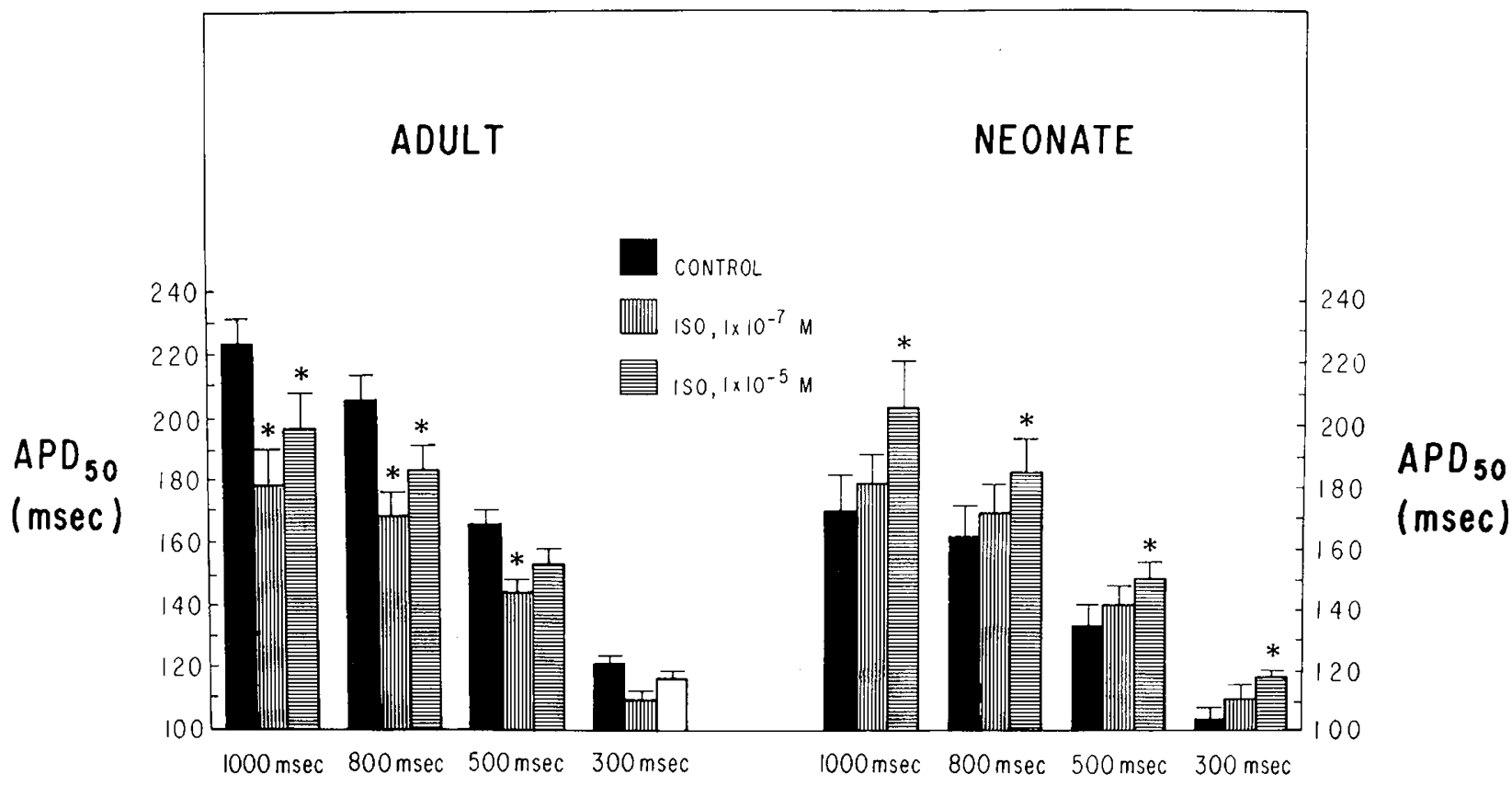

$\mathrm{CL}$

$C L$

Fig. 3. The effects of drive cycle length (horizontal axis) and of Iso on action potential duration measured to $50 \%$ repolarization (vertical axis). Results are presented for seven adult and seven neonatal fibers. As expected, driving the PF at progressively shorter cycle lengths significantly reduced action potential duration. In adults, Iso significantly accelerated repolarization at all cycle lengths $(p<0.01$, ANOVA). The asterisks indicate those values in Iso that differed significantly from control $\left(p<0.1\right.$, Scheffé). Moreover, at $\mathrm{CL}=1000 \mathrm{~ms}$, APD in Iso, $1 \times 10^{-5} \mathrm{M}$, while significantly shorter than control, was longer than in isoproterenol, $1 \times 10^{-7} \mathrm{M}(p<0.1$, Scheffé). In neonates, Iso significantly increased APD at all cycle lengths ( $p<0.01$, ANOVA). The asterisks indicate those values in Iso that differed significantly from the control values ( $p<0.1$, Scheffé). In addition, at $C L=1000 \mathrm{~ms}$, the value in Iso, $1 \times 10^{-5} \mathrm{M}$ was significantly longer than that in $1 \times 10^{-7} \mathrm{M}(p<0.1$, Scheffe $)$.

Table 3. Effects of Ach on transmembrane action potential characteristics of adult and neonatal PF (mean $\pm S E$ )

\begin{tabular}{|c|c|c|c|c|c|c|}
\hline $\begin{array}{c}\text { Ach } \\
\text { concentration }\end{array}$ & $\begin{array}{l}\text { MDP } \\
(-\mathrm{mV})\end{array}$ & $\begin{array}{l}\text { Amp } \\
(\mathrm{mV})\end{array}$ & $\begin{array}{r}\dot{\mathrm{V}}_{\max } \\
(\mathrm{V} / \mathrm{s}) \\
\end{array}$ & $\begin{array}{l}\mathrm{APD}_{50} \\
(\mathrm{~ms})\end{array}$ & $\begin{array}{c}\mathrm{APD}_{100} \\
(\mathrm{~ms})\end{array}$ & $\begin{array}{c}\text { Plateau } \\
(\mathrm{mV})\end{array}$ \\
\hline \multicolumn{7}{|l|}{ Adult PF } \\
\hline & $(n=16)$ & $(n=16)$ & $(n=15)$ & $(n=16)$ & $(n=16)$ & $(n=14)$ \\
\hline Control & $91 \pm 2$ & $130 \pm 2$ & $616 \pm 29$ & $211 \pm 4$ & $342 \pm 7$ & $6 \pm 2$ \\
\hline \multirow[t]{2}{*}{ Ach $10^{-7} \mathrm{M}$} & $92 \pm 2$ & $131 \pm 2$ & $646 \pm 32$ & $208 \pm 4$ & $336 \pm 7$ & $8 \pm 1$ \\
\hline & $(n=13)$ & $(n=13)$ & $(n=11)$ & $(n=13)$ & $(n=13)$ & $(n=12)$ \\
\hline Control & $89 \pm 2$ & $129 \pm 2$ & $660 \pm 31$ & $221 \pm 8$ & $348 \pm 11$ & $9 \pm 2$ \\
\hline Ach $10^{-5} \mathrm{M}$ & $89 \pm 2$ & $129 \pm 2$ & $678 \pm 33$ & $224 \pm 10$ & $350 \pm 12$ & $11 \pm 2$ \\
\hline \multicolumn{7}{|l|}{ Neonatal PF } \\
\hline & $(n=9)$ & $(n=9)$ & $(n=8)$ & $(n=9)$ & $(n=9)$ & $(n=9)$ \\
\hline Control & $89 \pm 2$ & $128 \pm 3$ & $504 \pm 28$ & $162 \pm 4$ & $276 \pm 6$ & $7 \pm 1$ \\
\hline \multirow[t]{2}{*}{ Ach $10^{-7} \mathrm{M}$} & $89 \pm 2$ & $129 \pm 3$ & $506 \pm 25$ & $164 \pm 5$ & $278 \pm 5$ & $9 \pm 1$ \\
\hline & $(n=11)$ & $(n=11)$ & $(n=10)$ & $(n=11)$ & $(n=11)$ & $(n=9)$ \\
\hline Control & $90 \pm 2$ & $126 \pm 3$ & $520 \pm 37$ & $151 \pm 5$ & $252 \pm 6$ & $12 \pm 2$ \\
\hline Ach $10^{-5} \mathrm{M}$ & $89 \pm 2$ & $126 \pm 3$ & $512 \pm 37$ & $158 \pm 6$ & $254 \pm 5$ & $14 \pm 2$ \\
\hline
\end{tabular}

superfusion with Iso and Ach, $1 \times 10^{-5} \mathrm{M}$, was significantly different $(p<0.01)$ from that with Iso alone (Fig. $4 A)$. A similar difference was seen for $\operatorname{APD}_{100}(p<0.01)$ (data not shown). No significant age-related effects were noted on maximum diastolic potential, action potential amplitude, $\dot{\mathrm{V}}_{\max }$ or plateau height $(p>0.05)$. In contrast to the adults, the concentration-response curve for $\mathrm{APD}_{50}$ in the neonates during superfusion with Iso and Ach $\left(1 \times 10^{-5} \mathrm{M}\right)$ did not differ significantly from the response observed during superfusion with Iso alone (Fig. $4 B$ ). Additionally, no significant effects were detected in the other action potential parameters including $\mathrm{APD}_{100}$ measured in neonatal PF.

\section{DISCUSSION}

Information on the pre- and postnatal development of the autonomic nervous system is incomplete. Moreover, the study of the development of autonomic activity is complicated by interspecies differences in rates of sympathetic and parasympathetic development (21), state of maturity of neurohumoral control at the time of birth (22), and the extent of development of the organ system that is innervated (23). Whether the parasympathetic nervous system is mature in the early postnatal period in the dog or in man is controversial $(13,16,17,24-26)$. Danilo 

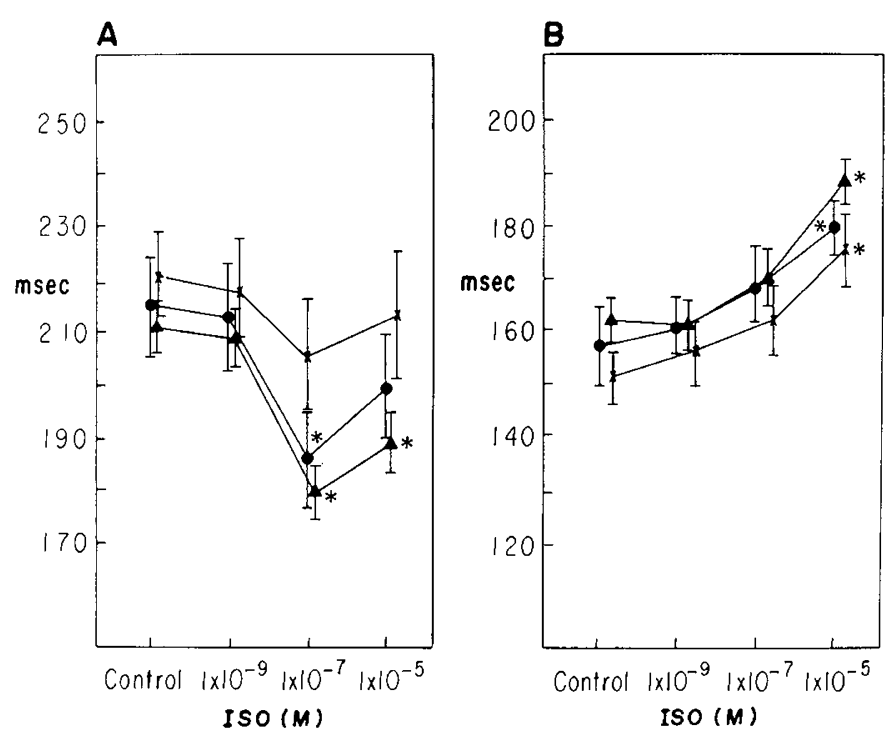

Fig. 4. The effects on $\mathrm{APD}_{50}$ of superfusing 16 adult $(A)$ and 11 neonatal $(B) \mathrm{PF}$ with Iso alone and in the presence of acetylcholine $(1 \times$ $10^{-7} \mathrm{M}$ and $\left.1 \times 10^{-5} \mathrm{M}\right) . A$, in the adult group, Iso alone and in the presence of acetylcholine $10^{-7} \mathrm{M}$ significantly shortened $\mathrm{APD}_{50}(p<$ 0.01 ). Ach $10^{-5} \mathrm{M}$ significantly antagonized the effects of isoproterenol on $\operatorname{APD}_{50}(p<0.01) . B$, in the neonatal group, Iso alone significantly prolonged $\mathrm{APD}_{50}(p<0.01)$. Ach $\left(10^{-7}\right.$ or $\left.10^{-5} \mathrm{M}\right)$ had no antagonistic effect on $\mathrm{APD}_{50}$ (mean $\pm \mathrm{SE}$ ). $\bullet$, superfusion with isoproterenol alone; $\boldsymbol{\Lambda}$, superfusion with Iso and Ach $10^{-7} \mathrm{M} ; \mathrm{X}$, superfusion with Iso and Ach $10^{-5} \mathrm{M} ;{ }^{*}=p<0.01$.

et al. (16) observed that the magnitude of the Ach-induced decrease in automaticity of canine PF was equal in the neonatal and adult age groups. However, Ach has been shown to have a greater negative inotropic effect with increasing maturation in canine hearts (25). In addition, adult dogs show a greater decrease in sinus rate in response to right and left vagal nerve stimulation than do 1- to 2-month-old puppies (13).

Development of the sympathetic nervous system is delayed in comparison to the parasympathetic; i.e. the sympathetic nervous system is immature at birth and develops over the first few months postnatally $(13,15,23,27,28)$. Rosen et al. (15) demonstrated automaticity of neonatal canine PF to be more sensitive to Iso than that of adults. Studies using sympathetic nerve stimulation have shown that the expected shortening of the canine ventricular muscle refractory period develops during the first 6 wk of life (23).

The present study has demonstrated two important differences between neonatal and adult canine cardiac PF. First, $\beta$-adrenergic stimulation with isoproterenol, alone, shortens action potential duration in the adults, whereas in the neonates action potential duration prolongs. Second, in addition to confirming that the parasympathetic mediator, Ach, significantly inhibits the electrophysiologic effects of Iso in the adult age group (3-7, 11, 29, 30), we found that Ach does not antagonize the electrophysiologic effects of Iso in the neonate.

The qualitative difference in the effect of Iso on action potential duration can be considered in light of the differences observed in plateau height and in the slope of phase 2. Iso increased plateau height significantly at both ages, but the magnitude of increase was greater for the neonatal fibers. The slope of phase two increased with exposure to Iso in adult PF; whereas no change was seen in the neonates. The more positive voltage of plateau origin and the lack of change in the slope of early repolarization resulted in prolongation of action potential duration in neonatal PF. Moreover, these effects of Iso on repolarization occurred over a wide range of stimulus rates, and at both ages the magnitude of the effect increased at the longer cycle lengths. Although we have not studied the mechanisms for these changes, $\beta$-adrenergic catecholamines are known to increase the slow inward current (31). Our results suggest that in the neonate, there may be greater sensitivity to the effects of $\beta$-adrenergic stimulation [already demonstrated for automaticity (15)] resulting in the greater plateau elevation. The lack of variation in the slopes of phases 2 and 3 in the neonates suggest that changes in repolarizing $\mathrm{K}^{+}$currents may not be occurring. Needless to say, voltage clamp studies will be required to resolve these questions.

In closing, the overall immaturity of both the sympathetic and parasympathetic nervous systems at birth and their different time courses of maturation probably provide the setting for the developmental changes we observed in their interaction. The developmental differences we have seen suggest that in the intact neonatal heart, one might not expect vagal stimulation to attenuate sympathetic effects significantly; such actions would only be expected in the adult. These differences between the two age groups suggest further that the changing autonomic interactions may serve as a modifier of the arrhythmogenic events as well as of normal rhythms that occur at both ages.

Acknowledgments. The authors express their gratitude to Dr. Irina Golyakhovsky for her assistance in performing certain of the studies and to Miss Andrea Diano for her careful attention to the preparation of the manuscript.

\section{REFERENCES}

1. Rosenblueth A, Simeone FA 1934 The interrelationships of vagal and accelerator effects on the cardiac rate. Am J Physiol 110:42-55

2. Levy MN, Zieske H 1969 Autonomic control of cardiac pacemaker activity and atrioventricular transmission. J Appl Physiol 27:465-470

3. Warner HR, Russell RO 1969 Effect of combined sympathetic and vagal stimulation on heart rate in the dog. Circ Res 24:567-573

4. Bailey JC, Watanabe AM, Besch HR, Lathrop DA 1979 Acetylcholine antagonism of the electrophysiological effects of isoproterenol on canine cardiac Purkinje fibers. Circ Res 44:378-383

5. Chamales MH, Gourley RD, Williams BJ 1975 Effect of acetylcholine on changes in contractility, heart rate and phosphorylase activity produced by isoprenaline, salbutamol and aminophylline in the perfused guinea-pig heart. Br J Pharmacol 53:531-538

6. Furey SA, Levy MN 1983 Interactions among heart rate, autonomic activity and arterial pressure upon the multiple repetitive extrasystole threshold in the dog. Am Heart J 106:1112-1120

7. Goldman S, Olajos M, Mackin E 1983 Cholinergic-sympathetic interactions in the left atrium and left ventricle of conscious dogs. J Pharmacol Exp Ther 225:219-223

8. Levy MN 1971 Sympathetic-parasympathetic interactions in the heart. Circ Res 29:437-445

9. Levy MN, Ng M, Martin P, Zieske H 1966 Sympathetic and parasympathetic interactions upon the left ventricle of the dog. Circ Res 19:5-10

10. Blair WR, Shimizu T, Bishop V 1980 The role of vagal afferents in the reflex control of the left ventricular refractory period in the cat. Circ Res 46:378386

11. Martins JB, Zipes DP 1980 Effects of sympathetic and vagal nerves on recovery properties of the endocardium and epicardium of the canine left ventricle. Circ Res 46:100-110

12. Pappano AJ 1977 Ontogenetic development of autonomic neuroeffector transmission and transmitter reactivity in embryonic and fetal hearts. Pharmacol Rev 29:3-33

13. Mace SE, Levy MN 1983 Neural control of heart rate: a comparison between puppies and adult animals. Pediatr Res 17:491-495

14. Friedman W 1972 The intrinsic physiologic properties of the developing heart. Prog Cardiovasc Dis 15:87-111

15. Rosen MR, Hordof AJ, Ilvento JP, Danilo P 1977 Effects of adrenergic amines on electrophysiological properties and automaticity of neonatal and adult canine Purkinje fibers: evidence for alpha- and beta-adrenergic actions. Circ Res 40:390-400

16. Danilo P, Rosen MR, Hordof AJ 1978 Effects of acetylcholine on the ventricular specialized conducting system of neonatal and adult dogs. Circ Res 43:777-784

17. Rosen MR, Merker C, Gelband H, Hoffman BF: 1973 Effects of procainamide on the electrophysiologic properties of the canine ventricular conducting system. J Pharmacol Exp Ther 185:438-466

18. Morikawa Y, Rosen MR 1984 Developmental changes in the effects of lidocaine on the electrophysiological properties of canine Purkinje fibers. Circ Res 55:633-641

19. Untereker WJ, Danilo P Jr, Rosen MR 1984 Developmental changes in action potential duration, refractoriness, and conduction in the canine ventricular conducting system. Pediatr Res 18:53-58

20. Snedecor GW, Cochran WG 1987 Statistical Methods. Iowa State University 
Press, Ames, IA

21. Vlk J, Vincenzi FF 1977 Functional autonomic innervation of mammalian cardiac pacemaker during the perinatal period. Biol Neonate 31:19-26

22. Assali NS, Brinkman, CR, Woods, JR, Dandavino A, Nuwayhid B 1977 Development of neurohumoral control of fetal, neonatal and adult cardiovascular functions. Am J Obstet Gynecol 129:748-759

23. Kralios FA, Millar CK 1978 Functional development of cardiac sympathetic nerves in newborn dogs: evidence for asymmetrical development. Cardiovascular Res 12:547-55

24. Smith RB 1970 The development of the intrinsic innervation of the human heart between the 10 and $70 \mathrm{~mm}$ stage. J Anat 107.271-279

25. Urthaler F, Walker AA, James TN 1980 Changing negative inotropic effect of acetylcholine in maturing canine cardiac muscle. Am J Physiol 238: $\mathrm{HI}-\mathrm{H} 7$

26. Walker D 1969 Functional development of the autonomic innervation in the human heart. Biol Neonate 25:31-43

27. Dail WG Palmer GC 1973 Localization and correlation of catecholaminecontaining cells with adenyl cyclase and phosphodiesterase activities in the human fetal heart. Anat Rec 177:265-288

28. Gennser G, Nilsson E 1970 Response to adrenaline, acetylcholine and change of contraction frequency in early human fetal hearts. Experentia 26:11051107

29. Gilmour RF, Zipes DP 1984 Evidence for pre-junctional and post-junctional antagonism of the sympathetic neuroeffector junction by acetylcholine in canine cardiac Purkinje fibers. J Am Coll Cardiol 3:760-765

30. Kolman BS, Verrier RL, Lown B 1975 The effect of vagus nerve stimulation upon vulnerability of the canine ventricle: role of the sympathetic parasympathetic interactions. Circulation 52:578-585

31. Noble D 1975 The Initiation of the Heart Beat. Clarendon Press, Oxford, 1975 